\title{
Attributes of Affective E-learning Behavior: Emerging Issues Beyond Teaching and Learning
}

\author{
Ali Kamali \\ Missouri Western State University, Saint Joseph, USA
}

\begin{abstract}
Many studies have focused on factors affecting e-learning and its effectiveness by comparing e-learning with face-to-face traditional classes. This study, however, aspires to contribute to the literature by exploring factors that contribute to student success in the e-learning environment. This study tested the assumption that a student's success in e-learning is a function of the specificities that are linked to this pedagogical model. It further postulated that these attributes are outcomes of an affective learning behavior. Data for this study were collected from a random sample of 486 respondents (close to $10 \%$ of the total student population) in a small university. The empirical data helped map out the hierarchy of the attributes that contribute to the development and experiences with e-learning. This study further provided suggestions to improve the areas that seem essential for a successful e-learning environment.
\end{abstract}

Keywords: e-learning, affective learning, performance outcomes

\section{Introduction}

Recently, many educators have been inspired by the idea that utilizing computers and information technology (i.e., e-learning) enhances their teaching and facilitates student learning. They have resorted to a form of constructivist approach to pedagogy that verified the specificities of e-learning that could help improve content delivery and enhance the relationship between teaching and learning. Researchers also attempted to legitimize e-learning by comparing e-learning's effectiveness with that of the face-to-face traditional classroom. E-learning's effectiveness has often been looked at suspiciously. This is natural, as is the case with all newly developed pedagogies, but this suspicion has led to an exorbitant amount of time and efforts invested in researching e-learning, which in turn has led to the generation of diverse opinions and often contradictory findings. The common theme in the preponderance of research on e-learning has mainly been the justification that e-learning is a legitimate and effective pedagogical strategy, and that it is here to stay.

Since this point has already been established in the literature, the intention of this study is not to support or discredit e-learning. It has already been established in the literature that managing an e-leaning environment is challenging and could often be inefficient, passive, and unstructured. The simplicity of most virtual learning environments, as Badge, Cann, and Scott (2005) have observed, has led academic staff to teach themselves the "hows" of the system, which resulted in poor pedagogical development, ending only in the creation of an electronic document repository in place of a viable teaching-learning environment. If this is the case, then

Ali Kamali, Ph.D., distinguished professor, Department of Economics, Political Science \& Sociology, Missouri Western State University. 
suspicion regarding e-learning's effectiveness is reasonable because facilitators are not fully utilizing the gamut of potentially useful platforms of the available e-learning pedagogical tools; instead, they are trivializing it.

Conversely, this study aims to explore attributes of effective teaching. This objective is based on the awareness that concerned educators are interested in witnessing an intellectual growth in their students regardless of the means employed for achieving this purpose; and that advancements in computers and information technologies have contributed to learning in a customized, on demand, and flexible manner. Also, the fact that the number of online course offerings across the nation has increased by an average yearly growth of $30 \%$ in the past few years (Allen \& Seaman, 2013) is another reason for being concerned with exploring attributes of an affective learning environment.

Given the above, it would appear that e-learning is here to stay; and many educators want to be part of these new developments in education technology. However, whether e-learning is able to create in students the ability to independently generate knowledge and develop a deeper intellectual curiosity is another question all together. This is not to discredit e-learning; rather, to encourage an interest in exploring the pedagogical factors that can contribute to cultivating a learner's willingness to be engaged and immersed in learning scenarios even if it is in a virtual teaching-learning environment.

\section{Literature Review}

The preponderance of research on e-learning is a comparison of e-learning with face-to-face traditional teaching-learning modules. Although e-learning has its own challenges and specificities, the common thread in the literature on effective teaching is that "good teaching is always good teaching" (Driscoll, Jicha, Hunt, Tichavsky, \& Thompson, 2012, p. 3). As a result, many researchers have looked at e-learning's effectiveness suspiciously; hence, questioning, by conjecture, if "e-learning is (good) learning". However, many have found that e-learners, compared to their face-to-face counterparts, are more able to retain information and apply the knowledge.

Although current research supports e-learning, studies that attempted to legitimize e-learning predominantly reflect students' perceptions and their acceptance of, or satisfaction with, e-learning. This is evident from the list of pertinent variables that Sun, Tsai, Finger, Chen, and Yeh (2008) reviewed (e.g., instructor attitude toward e-learning, perceived e-learning course flexibility, perceived e-learning course quality, perceived usefulness, perceived ease of use, and perceived satisfaction). A verification of the importance of the skills learned as a measure of e-learning's success has remained silent in the literature. In addition, the empirical factors affecting e-learning's success are missing in the preponderance of these studies (e.g., Driscoll et al., 2012; Fu, Su, \& Yu, 2009; Sun et al., 2008; to name but a few).

Other researchers-e.g., Floyd, Harrington, and Santiago (2009) — who focused on e-learning per se, equated e-learning with two types of learning: (a) "deep learning"; and (b) "surface learning". Borrowing from the literature, they found that perceived course value and student engagement to be two elemental factors for successful instructional conditions that sustain the student interest in the course. Although their research focused on these two concepts independent of one another, Floyd et al. (2009) further contended that paying attention and being motivated lead to "deep learning". Likewise, Conrad (2002), Conrad and Donaldson (2004), Handelsman, Briggs, Sullivan, and Towler (2005), Mason (2011), and Richardson and Newby (2006), who examined "attention" and "motivation", observed that these latter factors are contributing more to a deeper understanding of the course materials. 
A prevailing theme in research on e-learning is the reliance on the end of the semester course evaluations. The national debates concerning these evaluations point to the biases embedded in these measures of effectiveness. Clearly, satisfaction with a course does not reflect self-efficacy, i.e., the study skills or the skills for applying the course contents. Therefore, more research in these areas of e-learning pedagogy is needed that can shed light on the methods of enhancing a learner's educational experiences (Song, Singleton, Hill, \& Koh, 2004).

Moreover, the review of the literature points to three empirical (methodological) shortfalls in e-learning research that need careful scrutiny: 1. An assessment (either comparing online and face-to-face classes or focusing on each module independently) of the effects of a "course value" to the learner and his/her "engagement" with the course has not been fully researched; 2. A verification of the correlation between a course value and the learner's engagement as a measure of the interest in deeper learning has also remained silent; and 3. The literature on e-learning contains diverse definitions of pertinent concepts. For example, course value is conceptualized in the literature as being determined based on the challenges the course poses; and whether the course contents and management can generate an interest in the learner. The prevailing nominal definitions of "engagement" seem to be connectivity with the course materials (Herrington, Oliver, \& Reeves, 2003), which is also defined as forms of participation in an online discussion forum (Mason, 2011) or checking the course materials daily. The definition of "engagement" ranges from being involved in critical thinking activities and problem solving to applying the concepts as a knowledge-based skill. Conrad and Donaldson (2004) further indicated that learners' level of engagement with a course is dependent on how comfortable they feel with the amount of preparation time and the role of the instructor as a facilitator.

In summary, research on e-learning is diverse; the diversity of the conceptual definitions in these studies has also contributed to the diversity of findings on e-learning (Bennett, Harper, \& Hedberg, 2001; Conrad \& Donaldson, 2004; Floyd et al., 2009; Herrington et al., 2003; Mason, 2011; Sanders \& Lafferty, 2010). This situation, in turn, supplanted the production of a unified theory of e-learning that could capture the collective essence of diverse conceptualizations.

\section{The Theoretical Model}

The body of the available knowledge on e-learning verifies that it has radically transformed the modes of information generation and delivery; and it has made available diverse means of delivery in a flexible and portable manner. Literature review also showed that studies of e-learning are inclined to focus on separate ideas and see each as the reasons for e-learning's success. They have independently, but partially, contributed to the understanding of the critical factors affecting e-learning's effectiveness and its success as an information generation and delivery tool. Measures of e-learning also focused on different actors, such as learners, facilitators, or stakeholders (i.e., the decision-making layers, such as university officials and board members), and different conceptualizations.

The value of the existing research on e-learning is undeniable and has been a source of inspiration in this study. However, this research does not claim to offer a unified theory of e-learning - that would be a pretentious and ambitious undertaking which may not render useful results because of the ubiquitous nature of e-learning. Quite the opposite, this research treats e-learning as a facilitator-learner endeavor with an emphasis on learner-centered activities. Hence, it examined those aspects of e-learning that could be perceived as shortfalls in the literature. This stemmed from the curiosity about the deciding factors that could be found in a workable e-learning environment. 
The main theoretical framework is, therefore, developed based on the assumption that a solid pedagogical content (i.e., course quality) contributes to a robust e-learning environment, thereby increasing the course value (Hay et al., 2008; Stross, 2011) and the resultant performance in the course. This attribute is called affective learning engagement (ALE), in this study, which means the devotion to a course, the value place on a course, and the investment that one makes in a course in order to increase self-efficacy - a self-regulatory tendency developed in a learning environment - and expediency; all of which inadvertently enhance one's performance in an e-learning environment.

While the main goal of this study was to explore factors affecting academic performance in an e-learning environment, a latent goal of this study became the verification and recognition of a hierarchy of the factors that seemed to be more relevant to student success in a student-centered e-learning environment. Here, the emphasis is on the vital role played by the facilitator in creating such a learning environment and the delivery of information.

In summation, it is postulated that ALE is a function of the learner's devotion (i.e., willingness to immerse in learning scenarios), self-efficacy (i.e., the extent of maturity and self-discipline required in an e-learning environment or the independence for a self-paced and self-regulated environment), and expediency (i.e., a conscious effort to stay up-to-date). Borrowing from Díaz and Entonado (2009), this study proposes that learners perform better in the e-learning environment if they are engaged with the course materials on a regular or daily basis, which is both a result and an outcome of the value placed on a course. To verify the above assumptions, the following hypotheses were tested:

H.1: Successful performance in an e-learning environment depends on the learner's ALE with the course (i.e., his/her engagement and the value placed on a course).

The literature reviewed here pointed out the absence of empirical studies that verified the relationship between a course value and the amount of engagement in the course. Hence, Hypothesis 1 was further clarified in terms of the following sub-hypotheses:

H.1.1: The greater the value of a course to the learner, the greater the frequency of engagement is in the course;

H.1.2: Successful performance in e-learning is a function of the course value;

H.1.3: Successful performance in e-learning is a function of engagement in a course.

Two intervening variables - i.e., efficacy and expediency - were also included in this equation for their relevance to the overall theoretical scheme, which led to testing the following hypotheses:

H.2.1: E-learners who are engaged in the course and perceive the course as highly valued meet the demands of a course more efficiently;

H.2.2: E-learners who are engaged in the course and perceive the course as highly valued meet the demands of a course more expediently.

Since the model suggests a reciprocal affinity between efficiency and expediency (H.3), it is further hypothesized that:

H.3.1: Efficient e-learners are more likely to perform better in an e-learning environment;

H.3.2: Expedient e-learners are more likely to perform better in an e-learning environment.

In summary, the collective assumption in these hypotheses points the importance of a learner-centered environment in e-learning. Figure 1 shows a summary presentation of this model. 


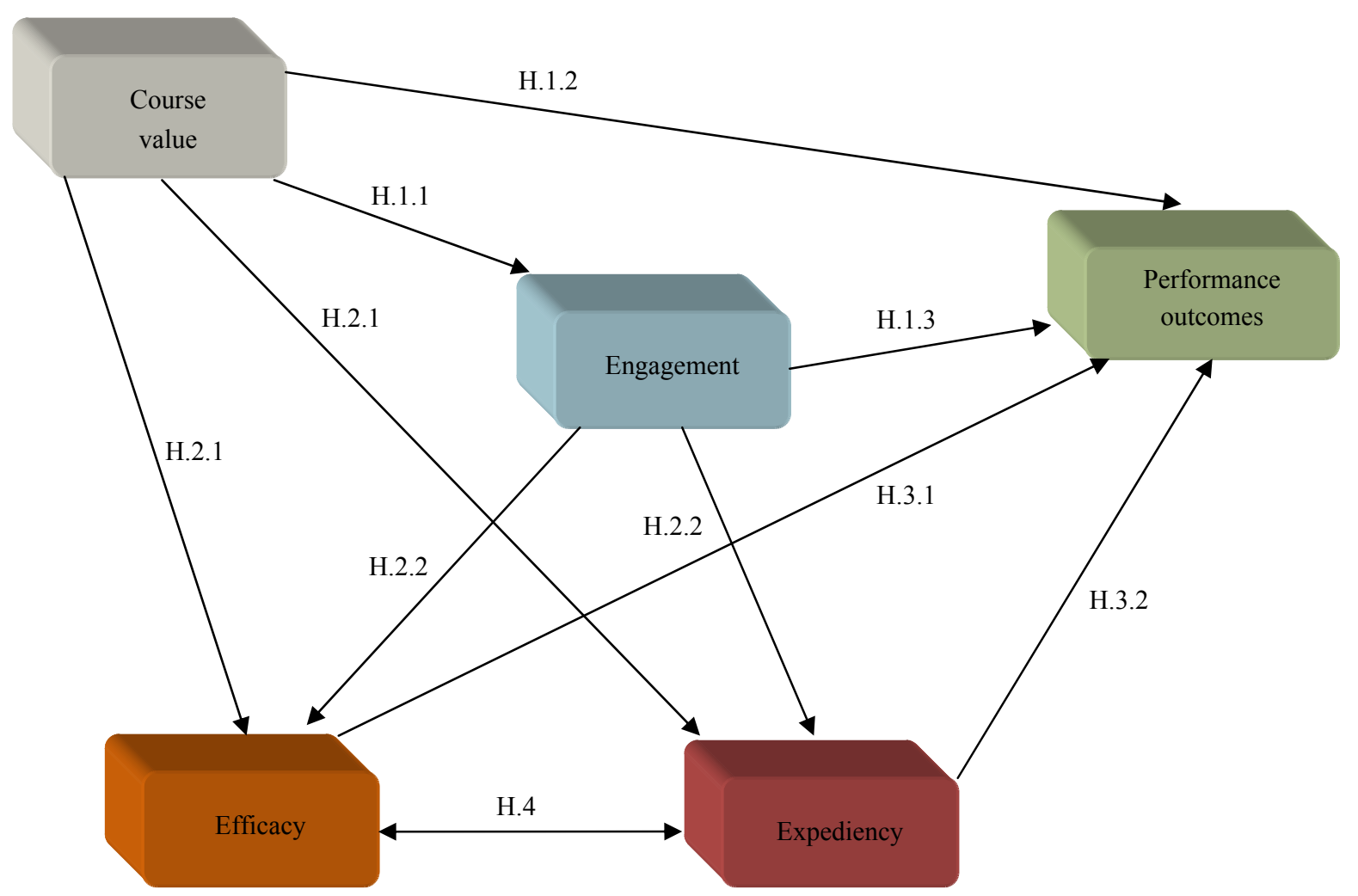

Figure 1. The theoretical model.

\section{Methodology}

The data for this study were collected via a self-administered questionnaire, which contained quantitative measures of the constructs explored in this study. The questionnaire measured variables of ALE, expediency, self-efficiency, and learner's success in an e-learning environment. After piloting the questionnaire, problematic or vague questions were rephrased, simplified, or eliminated.

\section{Sample and Data}

The data for this study were collected from a sample of the student population in a small midwestern university in the Fall Semester, 2012. Classes that met at 10:00 a.m. on Mondays were drawn randomly in order to avoid duplicating respondents. Only the 11:00 o'clock sections of the same courses were selected to increase the sample size for reliability. A total of 486 respondents made up the sample for this study (close to $10 \%$ of the total student population), which sufficiently ensures consistency in reliability (Monette, Sullivan, \& DeJong, 2010). Since data analysis focused on experiences with e-learning, only respondents who had prior experience(s) with e-learning were included in the study in order to make the sample more relevant. Of those surveyed, $77.8 \%$ were traditional students, i.e., typically 18-24 years of age who enter the university with no delay from high school, may work part-time, and are financially dependent (Deil-Amen, 2011). This ratio closely resembles the university's traditional-nontraditional student ratio of approximately $75 \% / 25 \%$. In addition, $62 \%$ of the respondents were females. The participants were equally distributed across different levels of class status - i.e., freshman, sophomore, junior, and senior-by approximately $25 \%$ of the sample respectively. 


\section{Variables and Measures}

Four additive constructs were created in order to verify the theoretical framework and to test the hypotheses of this study:

1. Engagement or the learner's willingness to engage and immerse in learning scenarios or contents. Engagement in this study is measured based on the frequency of the utilization of synchronous and asynchronous modes of communication with the facilitators and/or with classmates particularly while participating in discussions and forums;

2. Course value was assessed based on the regularity with which one is devoted to a course by staying up-to-date with the course contents, time spent on studying the course materials, and the perceived notion of the respondents on the value of a course;

3. Self-efficiency was determined according to the habitual treatment of the course requirements. This included the degree of independence while completing a course requirement either individually or collaboratively, as well as the ability to follow instructions independently. Other relevant measures of self-efficiency (e.g., the ability to use an application or ease of access to the course materials) were not included in this study since all e-learners in this institution are proficient in navigating e-learning climates. This is determined based on a placement/proficiency test prior to enrollment;

4. Expediency was conceptualized to mean the regularity with which the learner can fulfill the course requirements. Finally, learner's performance outcome - an endogenous variable - was qualified based on the learner's success - i.e., the grade point average (GPA) in online and hybrid courses.

All measures in this study employed an ordinal level of measurement. The questions in the questionnaire were measured based a 5-point Likert scale. After creating the constructs, the scales were recoded into three hierarchical categories ranging from "Low", "Moderate", to "High". Items in each scale were cross-checked for internal consistency and error terms - all were statistically significant at $p<0.01$. No residual term associated with the independent variable was observed. Unqualified variables were eliminated from their respective construct. Because of the ordinal nature of the constructs, Spearman's Rho was utilized to obtain bivariate correlations between the constructs in the theoretical model.

\section{Limitations}

While developing this study's theoretical framework and the initial conceptualization, satisfaction with the e-learning environment was not envisioned to be relevant to the learner's success in e-learning. In retrospect, this seems significant in verifying the variances in the outcomes. Another missing point in this study is the distinction between the required classes for the majors and the electives, or courses listed as general studies or common curriculum as the course valuation.

\section{Analysis and Findings}

The first layer of analysis in this study tested the descriptive attributes of the e-learning constructs. Table 1 contains both percent and mean distributions of the respondents across different e-leaning constructs examined in this study.

According to the data in Table 1, 27.7\% reported high level of engagement with the courses; only $54.6 \%$ were moderately engaged. A majority of $71 \%$ rated the value of online and hybrid courses as moderate; only $15.1 \%$ rated the course value as high. A good many (69.3\%) viewed their management of the course 
moderately expedient; only $16.4 \%$ of the sample were highly expedient. Close to $58 \%$ reported being moderately efficient; only $32 \%$ indicated being highly efficient. A greater number of the respondents seemed to be modest about their academic behavior and performance.

Table 1

Descriptive Statistics: Percent Distribution of Respondents, Mean, and Standard Deviation

\begin{tabular}{lrlllll}
\hline Constructs & Low & Moderate & High & Total & Median & $S D$ \\
\hline Course value & $13.8 \%$ & $71.1 \%$ & $15.1 \%$ & $100 \%$ & 2.01 & 0.54 \\
Expediency & $14.3 \%$ & $69.3 \%$ & $16.4 \%$ & $100 \%$ & 2.02 & 0.55 \\
Efficiency & $4.1 \%$ & $57.7 \%$ & $38.2 \%$ & $100 \%$ & 2.34 & 0.56 \\
Engagement & $17.6 \%$ & $54.6 \%$ & $27.7 \%$ & $100 \%$ & 2.10 & 0.67 \\
\hline
\end{tabular}

The mean scores for these constructs also showed similar patterns of distribution of the respondents. The mean scores for course value and engagement were 2.01 and 2.02 respectively, indicating a normal distribution of the respondents. However, the responses to the measures of efficiency and expediency were skewed toward the higher end (2.10 and 2.34 respectively). Moreover, the small standard deviation scores point to the uniformity of the responses. Thus, the frequency distributions and the mean scores indicate that the respondents in general viewed themselves as moderately engaged, devoted, and efficient.

A second layer of analyses in this study included cross-checking the correlations between possible pairs of the constructs in the model (see Figure 2).

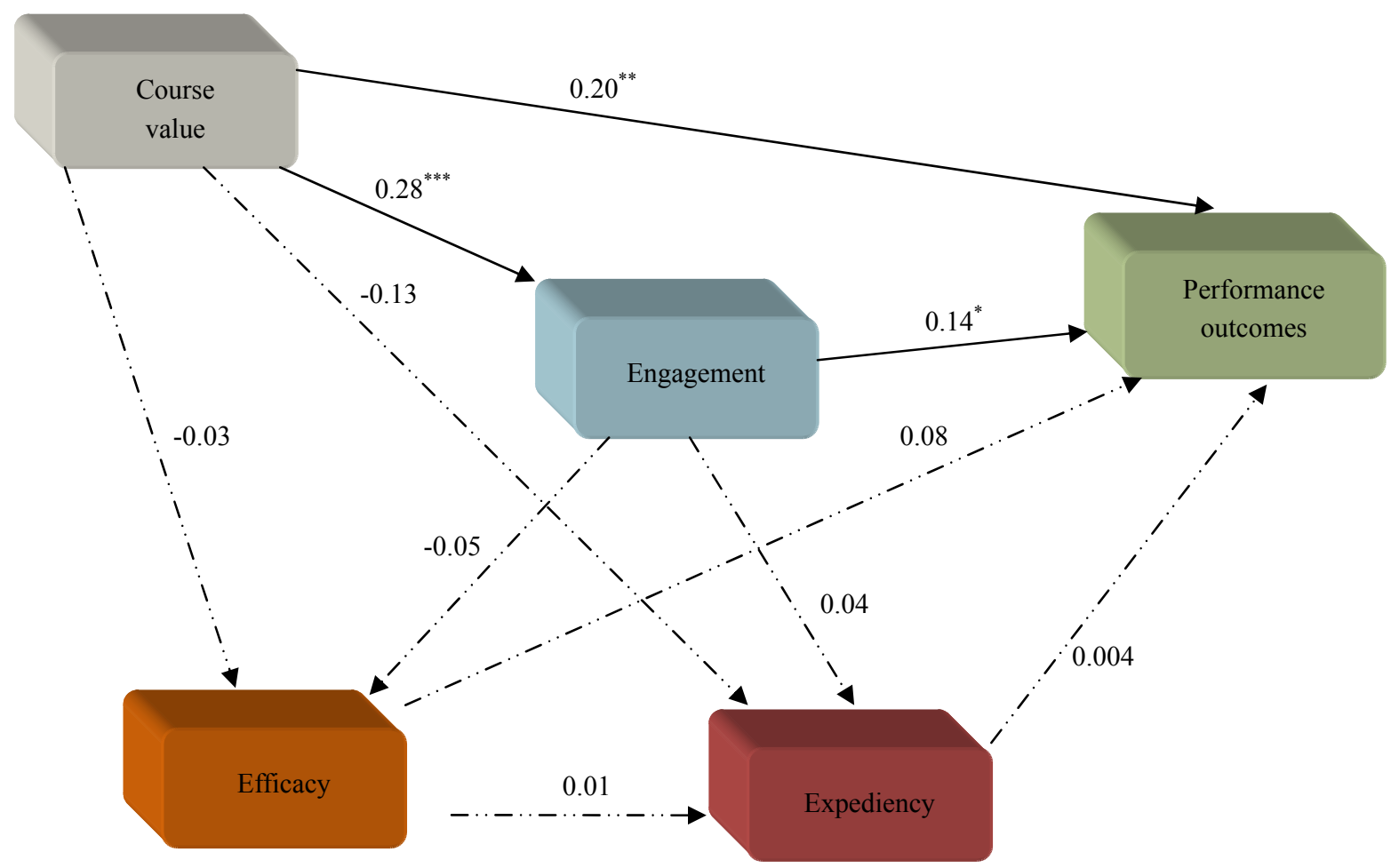

Figure 2. The theoretical model and the bivariate Spearman's Rho correlation coefficients (Notes. ${ }^{* * *}$ Correlation is significant at $p<0.001$ level (2-tailed); ${ }^{* *}$ Correlation is significant at $p<0.01$ level (2-tailed); and ${ }^{*}$ Correlation is significant at $p<0.05$ level (2-tailed). 
The bivariate coefficients presented in Figure 2 indicate a positive and statistically significant correlation between the main predictors of ALE (namely, course value and engagement) $(r=0.28 ; p<0.001)$; between course value and performance outcomes $(r=0.20 ; p=0.009)$; and between engagement and performance outcomes $(r=0.14 ; p=0.04)$. Hence, the data support Hypothesis 1 and its three sub-hypotheses.

Further analyses of the data indicated the existence of a statistically non-significant correlation between course value and efficiency $(r=-0.03)$; between engagement and efficiency $(r=-0.05)$; between course value and expediency $(r=-0.13)$; and between engagement and expediency $(r=-0.04)$. Thus, the empirical data did not support Hypothesis 2.1 and 2.2. In fact, all of these values were negative, showing inverse correlations, which warrant further investigation of the reasons for the discrepancy between the hypotheses and the empirical reality. However, it can be speculated that efficiency and expediency may be immaterial to producing quality outcomes (test results, assignments, projects, etc.). A good learner is a good learner regardless of the learning environment. This was evident when the overall GPA with the online GPA was cross-checked. The overall GPA was strongly correlated with the GPA accumulated in online or hybrid classes $(r=0.47 ; p<0.001)$.

The bivariate analyses between possible pairs of efficiency, expedience, and performance outcomes showed almost nonexistent and statistically insignificant correlations among these latter three constructs. Thus, the empirical data did not support Hypothesis 3 and its sub-hypotheses 3.1 and 3.2. These findings seem to contradict commonsense values that treat efficiency and expedience as core values in academic culture. One explanation is the assumption of meeting the deadlines. If a learner can submit quality work even under time constraints, then efficient time management or expediency may render useless or irrelevant in determining the outcomes. Perhaps future research in this area may shed light on this issue.

Although the descriptive statistics in Table 1 point to a homogenous distribution of the respondents across different constructs of e-learning examined in this study, the syllogistic approach could have rendered sufficient in explaining the variations. However, the observed inconsistent bivariate correlation patterns were alarming since they did not differentiate the hierarchy of the construct in the overall scheme of the model tested here. Since one of the aims in this study was to seek and verify the significance of the e-learning model presented here, there is a need to determine which construct(s) in this model is/are more important or significant in affecting student performance outcomes in an e-learning environment. Hence, regression analysis was employed as the third layer of analysis to examine the efficacy of the constructs (Cohen, 1988). Regression results are presented in Table 2 .

Table 2

Regression Coefficients for Construct Measurements ${ }^{a}$

\begin{tabular}{llllll}
\hline Constructs & $B$ & $S E$ & $\beta$ & $t$ & Sig. \\
\hline (Constant) & 2.20 & 0.69 & - & 3.204 & 0.002 \\
Course value & - & 0.43 & 0.19 & 0.20 & 2.25 \\
Efficiency & 0.24 & 0.16 & 0.12 & 1.494 & 0.14 \\
Expediency & 0.01 & 0.17 & 0.01 & 0.016 & 0.99 \\
Engagement & 0.15 & 0.15 & 0.08 & 1.02 & 0.39 \\
\hline
\end{tabular}

Notes. ${ }^{\text {a }}$ Dependent variable $=$ Performance; $R=0.25 ; R^{2}=0.06 ;$ Adjusted $R^{2}=0.03 ; F=2.65 ;$ and Sig. $=0.03$.

As is the case with any multivariate analysis, a major concern is the presence of the multicolinearity threat. However, the regression analysis indicated that the tolerance level was $>0.90$ for all constructs employed in 
this study. This indicates that the constructs used in this study are independent of one another.

The $F$ ratio in Table 2 verified the model examined in this study as significant $(F=27.52 ; p=0.000)$. However, the model predicts only a small portion of the variance in e-learning performance outcomes (only $6 \%$ ). On the other hand, test statistics showed a greater emphasis on the role that course value played in predicting performance outcomes. Course value seemed to be a more important predictor in the e-learning equation tested here $(\beta=0.20 ; p=0.02)$. The $t$ score for this construct also supported this finding $(t=2.25)$. (The $t$ score is greater than 1.96, which means that the confidence interval is greater than $95 \%$ ).

Overall, the regression analysis verified the bivariate findings. Since not all constructs in the model were significant in affecting performance outcomes, it was assumed that some unexplained portion of the variance in performance may be due to other factors, such as the course structure and its integrity. Thus, there seems to be a need for further research in this area. Nonetheless, the results in the regressions table corresponded with the bivariate coefficients.

\section{Conclusions and Policy Implications}

E-learning has been studied in many ways and forms. The aim in conducting this study was not to affirm or reject e-learning as a competing teaching/learning model, but to seek constructs that would enhance the learning process in the e-learning environment. Whether e-learning can replace face-to-face traditional classroom format is highly questionable (Zhang, Zhao, Zhou, \& Nunamaker, 2004), but the rising tendencies to incorporate information technology in daily activities lay claim to the idea that e-learning is here to stay. The penetration of consumerism in academia has become a compelling reason for the faculty to accept information technology and e-learning; hence, strategizing delivery methods that incorporate e-learning in ways that fit their needs is a trend that cannot be dismissed.

Regardless of one's approach to teaching-learning, a critical point in e-learning is the user's behavior. E-learning requires a degree of self-paced, disciplined structure; it is not an activity with which everyone is comfortable; nor have most students reached a level of competency and self-efficiency that regulates their engagement with the course materials. If employed in this fashion, as Zhang et al. (2004) exclaimed, e-learning can promote learners who could outperform learners in face-to-face traditional learning environments.

This study incorporated and tested constructs that could promote learners who could outperform those trained in face-to-face traditional environment. The constructs tested in this study are also potentially implementable in face-to-face traditional teaching-learning models. This was intended since the goal was to show that the method of delivery does not dictate the contents: Effective teaching (or learning) is determined by the environment within which knowledge is generated.

This study found that successful e-learning is a function (or product) of certain structural factors that reflected the characteristics of studious learners. Given this, and since many researchers found no significant differences between e-learning and face-to-face traditional classroom, it was assumed that ALE effectively creates a successful learning environment if implement even in face-to-face traditional classroom.

The literature suggests that effective e-learning is achievable through providing reliable and fluent communication channels and interaction maintenance among learners and between the facilitator and the learner. This study also showed that being attentive to a subject matter positively correlates with learning. The current study also contended that the potential for enhancing learning can be reached by widening the learner's options and permitting independence in learning. This suggestion proposes rediscovering the distinction 
between a "pupil" and a "student". In higher education, learners must seek knowledge independently instead of being "taught to". Perhaps, the former is more appropriate in e-learning, and a reason for ineffectiveness of other constructs.

The findings of study suggest that e-learning community building can be the foundation for creating and strengthening an ALE. Although the literature suggests many diverse variables and methods of community building, those that examined here as essential constructs (more specifically, engagement and devotion) seem to manifest themselves better in the notion of learning teams. Following the corporate model, some universities (e.g., University of Phoenix) have long been implementing this type of practices. However, the current research suggests a more aesthetic approach: Learners are more likely to develop fondness toward the course if they are engaged with others (i.e., their peers) in the process of generating knowledge.

In summary, learners are stakeholders in the advancement and growth of e-learning. Success in e-learning relates to recognizing and addressing the needs of the learners in general. Although the current research concentrated on learners with e-learning experiences, further need assessment of the students who are struggling with the fear of e-learning will shed light on the methods for successfully marketing e-learning. Perhaps, understanding and tackling the sources of students' fears and needs may prevent the high rate of failing grades and withdrawal or incomplete grades that seem to be characteristically associated with struggling e-learners (Wagner, Hassanein, \& Head, 2008).

\section{References}

Allen, E., \& Seaman, J. (2013). Changing course: Ten years of tracking online education in the United States. Bacon Survey Research Group. Retrieved November 25, 2013, from http://www.onlinelearningsurvey.com/highered.html

Badge, J., Cann, A., \& Scott, J. (2005). E-learning versus e-teaching: Seeing the pedagogic wood for the technological trees. Bioscience Education, 5, 5-6.

Bennett, S., Harper, B., \& Hedberg, J. (2001). Designing real-life cases to support authentic design activities. In G. Kennedy, M. Keppell, C. McNaught, \& T. Petrovic (Eds.), Meeting at the crossroads (pp. 73-81). Proceedings of The 18th Annual Conference of the Australian Society for Computers in Learning in Tertiary Education. Melbourne: Biomedical Multimedia Unit, University of Melbourne. Retrieved from http://www.ascilite.org.au/conferences/melbourne01/pdf/papers/bennetts.pdf

Cohen, J. (1988). Statistical power analysis for the behavioral science (2nd ed.). Hillsdale, N.J.: Erlbaum.

Conrad, D., (2002). Engagement, excitement, anxiety, and fear: Learners' experience of starting an online course. The American Journal of Distance Education, 16(4), 205-226.

Conrad, R., \& Donaldson, J. (2004). Engaging the online learner: Activities and resources for creative instruction. San Francisco, C.A.: Jossey-Bass.

Davies, J., \& Graff, M. (2005). Performance in e-learning: Online participation and student grades. British Journal of Education Technology, 36(4), 657-663.

Deil-Amen, R. (2011). The "traditional" college student: A smaller and smaller minority and its implications for diversity and access institutions University of Arizona, Center for the Study of Higher Education. Paper prepared for The Mapping Broad Access Higher Education Conference, Stanford University.

Díaz, A., \& Entonado, F. B. (2009). Are the functions of teachers in e-learning and face-to-face learning environments really different? Educational Technology \& Society, 12(4), 331-343.

Driscoll, J., Jicha, K., Hunt, A., Tichavsky, L., \& Thompson, G. (2012). Can online courses deliver in-class results? A comparison of student performance and satisfaction in an online versus face-to-face introductory sociology course. Teaching Sociology, 40(4), 312-331.

Floyd, S., Harrington, S., \& Santiago, J. (2009). The effect of engagement and perceived course value on deep and surface learning strategies. Informing Science: The International Journal of an Emerging Transdiscipline, 12, 181-190.

Fu, F. L., Su, R. C., \& Yu, S. C. (2009). EGame flow: A scale to measure learners' enjoyment of e-learning games. Computers \& Education, 52, 101-112. 
Garrison, D., \& Kanuka, H. (2004). Blended learning: Uncovering its transformative potential in higher education. Internet and Higher Education, 7, 95-105.

Handelsman, M., Briggs, W., Sullivan, N., \& Towler, A. (2005). A measure of college student course engagement. The Journal of Educational Research, 98(3), 184-192.

Hay, D., Kehoe, C., Miquel, M., Hatzipanagos, S., Kinchin, I., Keevil, S., \& Lygo-Baker, S. (2008). Measuring the quality of e-learning. British Journal of Educational Technology, 39(6), 1037-1056.

Herrington, J., Oliver, R., \& Reeves, T. (2003). Patterns of engagement in authentic online learning environments. Australian Journal of Educational Technology, 19(1), 59-71.

Ladyshewsky, R. (2004). E-learning compared with face to face: Differences in the academic achievement of postgraduate business students. Australasian Journal of Educational Technology, 20(3), 316-336.

Mason, R. B. (2011). Student engagement with, and participation in, an e-forum. Educational Technology \& Society, 14(2), 258-268.

Monette, D., Sullivan, T., \& DeJong, C. (2010). Applied social research: Tools for the human services (9th ed.). New York, N.Y.: Thompson.

Richardson, J. C., \& Newby, T. (2006). The role of students' cognitive engagement in online learning. The American Journal of Distance Education, 20(1), 23-37.

Rovai, A., \& Jordan, H. (2004). Blended learning and sense of community: A comparative analysis with traditional and fully online graduate courses. The International Review of Research in Open and Distance Learning, 5(2), 1-13. Retrieved May 27, 2013, from http://www.irrodl.org

Sanders, J., \& Lafferty, N. (2010). Twelve tips on usability testing to develop effective e-learning in medical education. Medical Teacher, 32, 956-960.

Singh, H. (2003). Building effective blended learning programs. Educational Technology, 43(6), 51-54.

Song, L., Singleton, E., Hill, J., Koh, M. H. (2004). Improving online learning: Student perceptions of useful and challenging characteristics. Internet and Higher Education, 7, 59-70.

Stross, R. (2011). In breaking down walls: Does online education sacrifice quality? Retrieved from http://www.openeducation.net /2011/02/10/in-breaking-down-walls-does-online-education-sacrifice-quality

Sun, P. C., Tsai, R., Finger, G., Chen, Y. Y., \& Yeh, D. (2008). What drives a successful e-learning? An empirical investigation of the critical factors influencing learner satisfaction. Computers \& Education, 50, 1183-1202.

Wagner, N., Hassanein, K., \& Head, M. (2008). Who is responsible for e-learning success in higher education? A stakeholder's analysis. Educational Technology \& Society, 11(3), 26-36.

Zhang, D., Zhao, J., Zhou, L., \& Nunamaker, J. (2004). Can e-learning replace classroom learning? Communication of the ACM, 47(5), 75-79. 